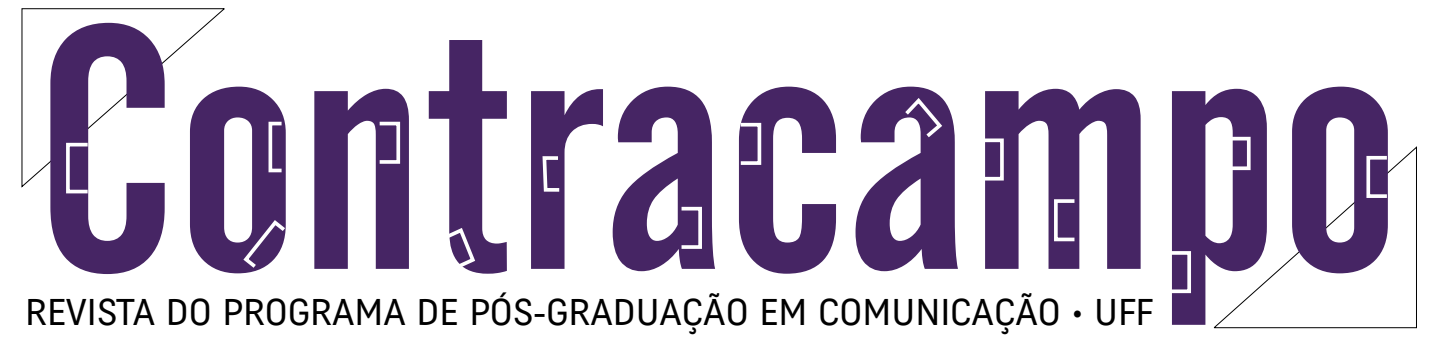

\title{
A representação identitária do adolescente em conflito com a lei na mídia paranaense
} The identity representation of
adolescents in conflict with the
law in Paraná/Brazil media

\section{Marcielly Moresco}

Mestra em Comunicação pela Universidade Federal do Paraná (UFPR). Relações Públicas pela Universidade Estadual de Londrina (UEL), Brasil. marciellymoresco@gmail.com

\section{Regiane Regina Ribeiro}

Doutora e Mestra em Comunicação e Semiótica pela Pontifícia Universidade Católica de São Paulo (PUC-SP). Professora do Programa de Pós-Graduação em Comunicação e do Curso de Comunicação Social da UFPR, Brasil.

regianeribeiro5@gmail.com

\section{PPG|COM}

Ao citar este artigo, utilize a seguinte referência bibliográfica:

MORESCO, Marcielly e RIBEIRO, Regiane. A representação identitária do adolescente em conflito com a lei na mídia paranaense. In: Revista Contracampo, v. 34, n. 3, ed. dez/2015mar/2016. Niterói: Contracampo, 2015. Págs: 81-94.

DOI: http://dx.doi.org/10.20505/contracampo.v34i3.797 Enviado em: 25 de jul. de 2015

Aceito em: 28 de out. de 2015

\section{Edição v.34 n.3/2015}

Contracampo e-ISSN 2238-2577

Niterói (RJ), v. 34, n. 3, dez/2015-mar/2016

A Revista Contracampo é uma revista eletrônica do Programa de Pós-Graduação em Comunicação da Universidade Federal Fluminense e tem como objetivo contribuir para a reflexão crítica em torno do campo midiático, atuando como espaço de circulação da pesquisa e do pensamento acadêmico. 


\section{Resumo}

Este artigo apresenta os resultados de uma investigação sobre a representação social e a identidade dos adolescentes em conflito coma leinos conteúdos da mídia paranaense, especificamente nos jornais Gazeta do Povo e Folha de Londrina. Pretendeu-se descrever a representação social desses sujeitos a partir das narrativas dos jornais e compreender como são estabelecidas suas identidades no meio impresso. Os procedimentos metodológicos adotados envolvem a análise de conteúdo (BARDIN, 1977; KRIPPENDORF, 1990; FONSECA JÚNIOR, 2012) de 39 textos jornalísticos (notícia, reportagem, artigo/opinião e entrevista) publicados no período de maio de 2013 a novembro de 2014. As conclusões apontam para uma representação social negativa e incriminadora dos adolescentes, indicando uma identidade construída por marcações sociais e simbólicas concentradas nas transgressões e na "punição".

\section{Palavras-Chave}

Comunicação; Identidade; Representação Social

\section{Abstract}

This article presents the results of an investigation into the social representation and the identity of adolescents in conflict with the law in the contents of Paraná/Brazil media, specifically in the newspapers Gazeta do Povo and Folha de Londrina. It aims to describe the social representation of these subjects from the narratives of the newspapers and understand how their identities are established in the print medium. The methodological procedures adopted involve content analysis (BARDIN, 1977; KRIPPENDORF, 1990; FONSECA JR, 2012) of 39 newspaper articles (news, report, article, editorial opinion and interview) published from May 2013 to November 2014. The conclusions point to a negative and incriminating social representation of the adolescents, indicating an identity constructed by social and symbolic marks concentrated in transgressions and "punishment".

\section{Keywords}

Communication; Identity; Social representation 


\section{Introdução}

Este artigo apresenta os resultados de uma dissertação de mestrado que abordou a representação social e a identidade dos adolescentes em conflito com a lei nos conteúdos da mídia. Das suposições de que diante da incerteza identitária, do preconceito, do estigma e do estereótipo, os adolescentes vestem a máscara do sujeito diferente e transgressor, podendo transformar suas atitudes em uma estratégia de subversão política e social', adveio o objetivo desta pesquisa, que consiste em refletir sobre esses sujeitos: analisar como é construída a identidade dos adolescentes em conflito com a lei nos conteúdos da mídia escrita paranaense.

A possibilidade de os adolescentes em conflito com a lei adotarem para si o estigma e estereótipo que são construídos pelos meios de comunicação e pela população permeou a problemática dessa investigação: Como se dá a construção identitária dos adolescentes em conflito com a lei nos conteúdos produzidos pelos jornais paranaenses? E, paralelamente, qual a identidade que essas representações ajudam a construir?

O percurso metodológico envolveu análise de conteúdo francesa (BARDIN, 1977) com a criação de categorias sistematicamente classificadas e analisadas a partir dos dois maiores jornais em número de circulação do Paraná: Gazeta do Povo e Folha de Londrina. O período de investigação envolveu os meses de maio de 2013 a novembro de 2014, sendo utilizados 39 textos, entre eles notícias, reportagens, artigos de opinião e entrevistas que apresentavam como tema central o adolescente em conflito com a lei.

O conceito de 'adolescente infrator/delinquente' no âmbito do senso comum indica um atributo que diferencia o adolescente desviante, isto é, aquele que não age dentro das expectativas sociais - o transgressor, do adolescente comum - aquele que possui os atributos e atitudes desejáveis pela sociedade. Entretanto, a infração não é só uma propriedade desses adolescentes específicos, uma vez que o comportamento "antissocial" e transgressor pode ser uma consequência necessária das condições sociais desfavoráveis, hostis e inadequadas que o jovem enfrenta na sociedade.

Nesse sentido, o cometimento de ato infracional pode tornar-se uma tentativa de pertencimento, fazendo com que o autor da contravenção passe a ser percebido pela sociedade e, às vezes, acolhido pelo sistema (CREAS, s/d).

Especificamente no Estado do Paraná, a população recenseada em 2010 foi de 10.444 .526 habitantes ${ }^{2}$, dos quais 10,7\% têm entre 12 e 17 anos de idade. Deste número, 897 são adolescentes cumprindo medidas socioeducativas em restrição e/ou privação de liberdade. A porcentagem é relativamente baixa, mas o protagonismo dos adolescentes na produção de violência e atos infracionais tem despertado inúmeras discussões em todos os âmbitos da sociedade. São debates de conjuntura legislativa e jurídica, mas também sobre os fatores de risco que implicam no comportamento desses meninos e meninas.

Os dados do Levantamento Anual da Coordenação-Geral do SINASE (BRASIL, 2013) indicam o aumento da taxa de restrição e privação de liberdade do adolescente que cometeu ato infracional: de 4,5\% em 2010 para 10,6\%; ao passo em que ao final de 2012 o aumento era de apenas 4,7\%, demonstrando um decréscimo na ascendente taxa de internação dos anos anteriores (BRASIL, 2013).

O Levantamento assinala a redução de atos graves contra o indivíduo entre 2010 e 2011 : homicídio caiu de $14,9 \%$ para 8,4\%; latrocínio de 5,5\% para 1,9\%; estupro de 3,3\% para 1,0\%; e lesão corporal de 2,2\% para 1,3\% e, em 2012, para 0,8\%. Demonstra-se, aqui, a contradição entre os dados apurados e a imagem do adolescente rotineiramente veiculada nos meios de comunicação como uma "ameaça crescente à sociedade".

No Paraná, os atos infracionais com maior incidência são o roubo, cometido por 333 adolescentes; o tráfico de drogas, por 207 menores de idade, e o homicídio, por 155 meninos e/ou meninas. Esses números, em termos nacionais, correspondem a 8.416 cometimentos por roubo; 5.881 por tráfico e 1.963 por homicídio (BRASIL, 2013). Esses dados são referentes aos atendimentos nos processos de internação, internação provisória, semiliberdade e atendimento inicial.

\footnotetext{
1 Parafraseando, nesse sentido, "Pele Negra, Máscaras Brancas” de F. Fanon em “O Local da Cultura” Homi Bhabha (1998).

2 IBGE, Censo Demográfico 2010. Disponível em: 〈http://www.ibge.gov.br/estadosat/perfil.php?sigla=pr〉. Acesso em: 12 fev. 2015.
} 
Paradoxalmente, o aumento da restrição e privação de liberdade corresponde, segundo o próprio SINASE, à utilização da internação como uma sanção, respondendo aos apelos pela redução da maioridade penal repercutidos na mídia. Observa-se que os meios de comunicação exercem influência também sobre o sistema socioeducativo. Kellner (2001) relembra que a cultura da mídia almeja sempre uma grande audiência, portanto, deve ser eco de assuntos e pautas atuais e que apresentam dados da vida social.

A ambição por uma identidade é negada a, priori, aos indivíduos que vivem na "subclasse"; isto é, uma posição inferior na hierarquia do poder. Fazem parte, nesse sentido, o próprio adolescente em conflito com a lei, a mãe solteira, o evasivo da escola, os desterritorializados, os moradores de rua, os refugiados, os usuários de drogas e todos aqueles exilados dos limites sociais que compõe o campo no qual as identidades podem ser reivindicadas pelos sujeitos adequados e admissíveis. Sendo assim, a "identidade da subclasse" é a "ausência de identidade” (BAUMAN, 2005, p. 46). Quer dizer, esses grupos não teriam o direito de reivindicar sua própria identidade, ou de tentar representá-la, uma vez que são sujeitos marginalizados.

\section{Identidade das minorias}

Parte-se da perspectiva de que a identidade é formada a partir de sistemas culturais, compreendida como culturalmente formada, ligada à discussão das identidades que se formam no cotidiano do sujeito. Logo, "são pontos de identificação, os pontos instáveis de identificação ou sutura, feitos no interior dos discursos da cultura e da história. Não uma essência, mas um posicionamento" (HALL, 1996, p. 70).

Quando se considera a identidade pensada a partir da comunicação, tem-se o intuito de mostrar como a cultura da mídia é articulada com a construção de significados pelos sujeitos (KELLNER, 2001). Considerando a identidade como um processo de interações sociais complexas mediadas por signos, produzindo significados, apresenta-se, portanto, um fenômeno comunicacional. A construção de significados e de identidade das minorias é consequência de mediações - sobretudo as midiáticas - constituídas de mestiçagens e hibridações a partir de manifestações e representações sociais, especialmente as visuais e textuais (OROZCO, 2006).

Os adolescentes, ao ingressarem em práticas como o cometimento de atos infracionais, passam a construir e significar novas identidades e, para que haja o sentimento de pertencimento a um determinado conjunto de indivíduos, assumem uma imagem e utilizam os artefatos culturais desse grupo. Isto é, a identidade adotada pode ocorrer em função da marcação da diferença de outros adolescentes, do que "não sou". Essa construção de identidade é compartilhada, também, com a significação de identidades por meio da mídia.

Fanon, em Black Skin, White Masks (1986), em português Pele Negra, Máscaras Brancas, citado por Homi Bhabha em O Local da Cultura (1998), destaca que os grupos que vivem na "subclasse", quando são cultural e racialmente marginalizados, assumem a máscara ou a posição de minoria. Fazem isto não para negar sua diversidade, mas para anunciar a identidade cultural e sua diferença. Essa leitura também pode ser feita em relação ao(s) motivo(s) que leva(m) o adolescente a cometer o ato infracional: assumir uma identidade para realçar sua diferença, sua identidade construída pela sociedade.

Baseando-se nos Estudos Culturais, Larrain (2003) ainda chama a atenção para o conceito de identidade como a capacidade de construir uma narrativa de si mesmo ou do outro. Entretanto, o autor ressalta que essa capacidade só é adquirida em um processo de relações sociais mediadas pelas formas simbólicas. Martino (2010) vai mais adiante e define identidade como um discurso e que, por isso, ela é atrelada aos estudos da comunicação:

A narrativa é uma das principais atividades humanas. O tempo todo, das maneiras mais diversas, estamos reconstruindo a realidade como um discurso. Essa realidade do discurso, isto é, o real transplantado para um outro nível de apropriação cognitiva, é compartilhada pela comunidade de um tempo e um espaço constituindo o tecido narrativo, simbólico e imaginário de um grupo (MARTINO, 2010, p. 40).

Hall (1996; 2003) argumenta que o sujeito fala sobre a identidade a partir de uma posição histórica e cultural. Nesse sentido, duas perspectivas de se pensar a identidade cultural aparecem: a primeira no sentido de conceber uma cultura partilhada, ou seja, os sistemas culturais unificam os 
indivíduos em quadros de referência (mapas conceituais), isto é, têm sua identidade representada sob uma forma cultural que a reforce e a reafirme. E um exemplo atual dessa concepção são os movimentos sociais (feminista, anticolonialista, antirracista, anti-homofóbico, entre outros), bem como os produtos da cultura industrial (filmes, séries, telenovelas etc.).

A segunda concepção de identidade cultural se arquiteta "no que eu sou" - e com a intervenção da modernidade: "o que eu me tornei”. Isto é, as identidades culturais provêm de alguma parte e, portanto, possuem histórias, sofrendo modificações constantes (HALL, 1996, p. 69). A identidade, nesse caso, possui passado, e este não é negado, mas ela é reconstruída, reivindicada. Dessa forma, os sujeitos podem se posicionar a si próprios ou outro mediante àquela herdada. É, portanto, formada e transformada histórica e continuamente de acordo com a cultura que permeia o indivíduo (HALL, 2003).

No caso dos adolescentes, as identidades herdadas do meio em que viveram/vivem existem e, por estarem os jovens em um período da vida marcado por inquietações, dúvidas, vontade de mudar sua realidade, vão modificando-se, moldando-se conforme os novos espaços e grupos sociais com quem o sujeito interage.

A identidade não fixa, explicada a partir das oposições binárias marcadas pelo conceito de différence, de Jacques Derrida, implicam atos de inclusão e exclusão, como, por exemplo, quando o sujeito diz "o que é" também está dizendo "o que não é”. Ou seja, a diferença indica que a construção da identidade é formada relativamente a outras identidades que não constituem o sujeito (WOODWARD, 2014).

De modo que a identidade do adolescente transgressor dos limites da sociedade reúne a(s) identidade(s) que deseja para si, mas também a(s) identidade(s) do grupo social que frequenta, da comunidade, a identidade construída midiaticamente, pela sociedade que, consequentemente, são formadas por outras identidades que os excluem desses lugares e não-lugares.

\section{A representação social nos meios de comunicação}

A centralidade social e cultural dos meios de comunicação de massa fez com que questões complexas entre sociedade e comunicação emergissem e teorias sociais, tal como as representações sociais, foram necessárias para explicar as transformações nesse contexto. Nos meios de comunicação, as representações sociais, enquanto práticas sociais e, portanto, uma dimensão cultural ${ }^{3}$, possuem um aspecto significante que Ihes dá sentido, bem como constitui a interação entre os sujeitos consumidores de conteúdo e contribui na construção identitária de um grupo e/ou sujeito.

Para Serge Moscovici (2003), o fenômeno das representações sociais é característico das sociedades pensantes - "thinking society". O pesquisador busca na psicologia social exemplos de como ilustrar o papel e a influência da comunicação no processo de representações sociais e de como elas se tornam senso comum na sociedade contemporânea. Para o autor, a teoria da representação social não se preocupa com o que é comunicado, e sim, com a maneira com que se comunica os fatos e qual o significado que essa comunicação tem para o sujeito.

O conceito da representação social tem origem decorrente do fenômeno das representações coletivas de Émile Durkheim, de 1898. Para esse sociólogo, as representações coletivas constituíam formas de conhecimento - tanto do senso comum como do pensamento científico. $\bigcirc$ autor defende que as ideias são propriedade individual, no entanto, só reúnem significado e tornamse conscientes a partir do ponto de vista coletivo (DURKHEIM, 1970). Assim, as representações coletivas tornam-se formas de pensamento por meio das quais a sociedade expressa-se.

A maneira como os veículos de comunicação retratam os adolescentes supostamente infratores influencia o modo como esse sujeito é "visto" e "recebido" pela população. Portanto, apropriando-se de uma informação imediata do conteúdo noticioso, embora com menos detalhes e profundidade, essa compreensão vulgar, supostamente de uma maioria e de uma proposição "normal/anormal", ocasiona uma representação social movida pela espontaneidade da informação. Com isso, o senso comum possibilita ações sem reflexões ou opiniões rasas sobre o cometimento de ato infracional e os adolescentes, abrindo espaço para o estigma e o estereótipo.

3 Toda prática social contém uma dimensão cultural, pois toda conduta está significando algo, está participando de um modo diferencial de interações sociais. Entretanto, nem tudo nessas práticas sociais é cultura (ver mais em: CANCLINI, 2004, p. 37). 
A inter-relação entre as representações sociais a partir das estruturas da sociedade propõe novas formas comunicativas, resultando em novas representações. Um modelo brasileiro desse processo de integração entre esses elementos é a representação do jovem em "situação irregular", do "menor abandonado" ou do delinquente 4 arquitetada pelos Códigos dos Menores, os quais construíam uma identidade de sujeitos indesejados e ameaçadores do bem-estar da sociedade. Nesse caso, a estrutura e a organização para tratar dos interesses das crianças e adolescentes foram criadas e formadas por representações sociais, mas também por influências comunicativas que agem na sociedade. É uma relação na qual uma pode mudar a estabilidade da outra.

Um exemplo dessa transformação está na alteração do Decreto n $17943-A$, de 12 de outubro de 1927, que promulga o Código de Menores do Brasil posteriormente, revogado pela Lei no 6.697, de 10 de outubro de 1979, a qual origina o segundo Código de Menores do Brasil. O primeiro delimitava a tutela da criança abandonada e em situação irregular ao Estado, possuindo uma perspectiva higienista e autoritária, excluindo as políticas públicas. Já na década de 1970, visto a ineficácia das medidas protecionistas do menor de idade por parte do Estado e o surgimento de movimentos populares de defesa dos Direitos Humanos da criança e do adolescente, optou-se por lograr um novo Código com os mesmos aspectos de intervenção institucionalizada e militarizada, mas com proteção integral ao jovem e um poder maior do Estado sob a família.

À medida que os interesses humanos sobre aumentar o acesso aos direitos básicos e de proteção a essa população menor de idade geraram conflitos pelo país (movimentos sociais, mais tarde influenciados, principalmente, pela Convenção dos Direitos da Criança da da Organização das Nações Unidas - ONU), sob a configuração de novas formas de comunicação, alterou-se também a visibilidade desse sujeito e sua representação social, delimitando-se a transformação da estrutura e a organização das políticas.

Diante disso, em 1990, após a nova Constituição de 1988, o Estado promulga a Lei no 8.069, de 13 de julho de 1990, dispondo sobre o Estatuto da Criança e do Adolescente (ECA), desinstitucionalizando os meninos e as meninas, assegurando os direitos e deveres destes, definindo a idade de imputabilidade penal, promovendo abertura para políticas públicas comunitárias, além de estatais, entre outras providências. E, acentuadamente, a representação social vai construindo sujeitos de direitos, estabelecendo outra identidade para essa população até gerar novos debates sociais e influências comunicativas - como a que se vive contemporaneamente a respeito da imputabilidade do ECA, da redução da maioridade penal, entre outros - e trazer a possibilidade de novas transformações estruturais e de representação.

Atributos como "anormal", "delinquente", "selvagem" ou "desviante" são considerados estigmas e seus efeitos socialmente e psicologicamente no sujeito estigmatizado são depreciativos. O estigma "adolescente infrator", num primeiro momento, pode gerar discriminação e dificuldades na ressocialização, como na designação de um emprego, na frequência escolar, na interação social, no desempenho de tarefas coletivas, na vida em comunidade e, sobretudo, na diferença da identidade. Para Goffman (2012), estigma é uma relação entre atributo e estereótipo, constituise como uma ramificação das expectativas normativas das pessoas em relação à conduta e/ou caráter de outro indivíduo.

O estereótipo, por sua vez, é compreendido como uma falsa representação de uma dada realidade e, por ser ambivalente, garante sua reprodução sem detrimento em diversas conjunturas históricas e discursivas, segundo Bhabha (1998, p. 106).

Alguns veículos imagéticos disseminam o estigma e o estereotipo do jovem em conflito com a lei e de todo sistema de socioeducação, dramatizando as notícias e vitimizando os sujeitos, por exemplo. Essa disseminação, pelos meios de comunicação, das representações estereotípicas, estigmatizadas e inadequadas não só das crianças e adolescentes infratores, mas das mulheres, dos negros e negras, povos indígenas, comunidade LGBT e de outras comunidades, torna-se um problema para o processo democrático - o qual é, ou deveria ser, um regime para as minorias.

\footnotetext{
4 Termos utilizados desde o período anterior ao Estado Novo até início dos anos 1990, quando as lutas pelos Direitos Humanos iniciaram modificações nos verbetes alusivos aos meninos e às meninas menores de 18 anos.
} 


\section{Percurso metodológico}

A cobertura e a análise dos textos são avaliadas com base na técnica de Análise de Conteúdo, pois além de possibilitar quantificar de forma objetiva e sistemática as características dos materiais, mensurando e apresentando dados numéricos, é possível também qualificar de acordo com categorias pensadas especialmente a partir do referencial teórico aqui trabalhado. Ressalta-se que nessa investigação, são as narrativas jornalísticas sobre os adolescentes em conflito com a lei que estão sob análise.

No contexto de estudos da comunicação de massa, essa técnica cumpre com os requisitos da confiabilidade e da sistematicidade e, portanto, atende às características para essa investigação.

A análise de conteúdo é sistemática porque se baseia num conjunto de procedimentos que se aplicam da mesma forma a todo o conteúdo analisável. É também confiável - ou objetiva - porque permite que diferentes pessoas, aplicando e separando as mesmas categorias à mesma amostra de mensagens, possam chegar às mesmas conclusões (LOZANO, 1994 apud FONSECA JÚNIOR, 2012, p. 286, grifo nosso).

A Análise de Conteúdo pode ser definida como um conjunto de técnicas de pesquisas das comunicações (códigos linguísticos, orais, escritos, icônicos, outros códigos semióticos) cujo conteúdo das mensagens é descrito minuciosamente (BARDIN, 1977). Os trabalhos iniciais dessa técnica na área da comunicação, no século XIX, estiveram relacionados aos estudos do jornalismo sensacionalista (muckraking journalism) americano. A partir desse fenômeno, os analistas introduziram essa técnica também na pesquisa de opinião pública sobre os estereótipos sociais (como referência, a obra de Walter Lippman, Public Opinion, de 1922).

A partir das tendências metodológicas propostas por Bardin, a análise de conteúdo possui três fases cronológicas para seu desenvolvimento: 1) Pré-análise - planejamento do estudo com elaboração de um plano de análise envolvendo a leitura flutuante do tema, a escolha das matérias, a formulação dos objetivos e das hipóteses, constituição do corpus e elaboração de indicadores que comporão a dimensão e o direcionamento da análise, bem como as regras de codificação e de categorização do material; 2) Exploração do material - refere-se à análise, envolvendo principalmente a codificação e a categorização dos elementos que aparecem nas mensagens, obedecendo às regras previamente formuladas; 3) Tratamento dos resultados e interpretação - após a síntese e seleção dos resultados, utilizam-se operações estatísticas e/ou inferências de modo a interpretar os dados.

Após a constituição do corpus, a apreciação envolve a transformação dos dados de forma sistemática - a codificação - seguindo as regras de enumeração e classificação, com a finalidade de esclarecer as características do material selecionado.

A codificação, nesta investigação, compreendeu o recorte das unidades de registro (BARDIN, 1977), isto é, a escolha do material a partir das matérias de interesse para a pesquisa - sobre o tema acompanhado nesta pesquisa: "adolescentes em conflito com a lei". Para esse recorte se buscou, nas páginas online 5 , por meio da ferramenta "busca" ou "pesquise" todas as matérias referente a esse tema principal, no período pré-definido. Para a busca das matérias em cada site foram utilizadas palavras-chave relacionadas ao tema central: "adolescente em conflito com a lei"; "adolescente infrator"; "menor infrator".

A seleção dessas matérias envolveu alguns critérios metodológicos: todas as matérias sobre o universo da adolescência em contravenção são compiladas, exceto aquelas publicadas fora do período proposto - maio de 2013 a outubro de 2014. Notas, anúncios publicitários e cartas de leitores não são selecionados. Foram filtrados também os textos cuja cobertura principal não estava relacionada diretamente com o adolescente supostamente infrator.

A análise tem início a partir de maio de 2013, uma vez que havia uma quantidade significativa de informação circulando pelos meios de massa, projetos de lei solicitando alteração no ECA e na

5 Sites dos jornais pesquisados: Gazeta do Povo: <http://www.gazetadopovo.com.br/>. Folha de Londrina: 〈http://www.folhaweb.com. $\mathrm{br} />$. Para ter acesso ao material online na íntegra do jornal Folha de Londrina é preciso portar login e senha de assinante. O jornal Gazeta do Povo disponibiliza o material online gratuitamente. 
Constituição Federal, requerimentos protocolados aguardando debates sobre o tema ${ }^{6}$ e publicações nos jornais sobre adolescentes em conflito com a lei, requerendo dados mais aprofundados.

Para alcançar os objetivos propostos, isto é, identificar marcações sociais e simbólicas que possibilitam a construção identitária da minoria, foram monitorados alguns elementos relacionados à construção da identidade e específicos do universo dos adolescentes em conflito com a lei, como:

- atos infracionais (como são abordados);

- imagens e identificação dos adolescentes;

- termos pejorativos;

- tratamento dado aos adolescentes;

- maioridade penal.

Com isso, são escolhidas as unidades de contexto, as quais são necessárias para referenciar a conjuntura no qual as unidades de registro estão inseridas. Nesse caso, ao analisar as mensagens, a contextualização das palavras contidas no texto auxilia na compreensão do sentido que elas podem dar à construção identitária.

Os jornais que compunham a investigação são: Gazeta do Povo - jornal de circulação diária, em formato standard, sediado em Curitiba (PR), fundado em 3 de fevereiro de 1919. Atualmente, é o maior jornal do Paraná em números de circulação no Estado. Sua publicação é da Editora Gazeta do Povo S.A., pertencente ao Grupo Paranaense de Comunicação - GRPCOM. O jornal é composto pelos principais cadernos diários: Vida e Cidadania; Vida Pública; Economia; Mundo; Esportes; Caderno G; Opinião e Classificados. O caderno de notícias que mais apareceu na pesquisa sobre adolescentes em conflito com a lei é o Vida e Cidadania. Além dessas seções fixas, o veículo impresso mantém a publicação de diversas outras seções, bem como suplementos semanais, quinzenais e mensais; Folha de Londrina - jornal com impressão diária em formato standard e fundado na cidade de Londrina (PR) em 1948, por João Milanez, também fundador de rádio e televisão no Paraná. O veículo faz parte do Grupo Folha Comunicações, com o portal online $O$ Bonde. O jornal é composto pelos principais cadernos diários: Política; Geral; Mundo; Cidades; Economia; Esporte; Folha 2; Opinião. A Folha também possui diversas seções e cadernos semanais, bem como classificados. Os cadernos que mais apareceram na investigação são: Geral e Reportagem. Para o jornal, o caderno Geral aborda assuntos cotidianos e reportagens com relação ao dia a dia do leitor. O caderno Reportagem é uma publicação semanal, pautando temas de acordo com o debate na sociedade.

\section{O olhar sobre o processo: análise dos dados e resultados}

No total, foram identificados 39 textos distribuídos em seções e/ou cadernos temáticos nos dois jornais. Em sua maioria, os textos do jornal Gazeta do Povo são apresentados na seção fixa e diária intitulada Vida e Cidadania (14 textos); outras seções observadas foram Justiça e Direito (2), Opinião (3) e Artigo (3). Por sua vez, os textos do jornal Folha de Londrina aparecem, em maior número, na seção fixa e diária intitulada Geral (6) e na seção especial Reportagem (8), a qual abarca essencialmente esse gênero jornalístico. As demais seções notadas foram Política (1) e Opinião (2).

Das matérias reportagens analisadas, 88\% são informativas e apenas 12\% são estritamente opinativas. A Folha de Londrina traz mais reportagens, embora nenhuma seja de opinião. A Gazeta do Povo possui duas de opinião e quatro informativas.

Observa-se que as matérias policiais dos dois jornais estão incluídas na seção de cotidiano, a qual também engloba publicações de informações sobre adolescentes e atos infracionais. Nenhum dos dois jornais possui caderno específico para questões policiais.

Dentre as possíveis inferências sobre essa observação está o desejo dos jornais de apontar que infrações cometidas por adolescentes, e toda prática criminosa de adultos, são elementos do cotidiano social, presente no dia a dia do leitor/consumidor; ou os jornais desejam fomentar o debate social sobre os atos infracionais - tema que tem circulado com certa periodicidade pelos veículos de comunicação de massa nos últimos anos.

6 Informações sobre Projetos de Lei e Requerimentos sobre o tema podem ser acessadas na página da Câmara dos Deputados do Brasil: < http://www2.camara.leg.br/>. 
A reportagem policial em jornais brasileiros é datada no início no século XX, abordando, principalmente, os meninos de rua, os "desordeiros", os imigrantes esfaimados, os "vagabundos", a vacância dos negros, os mendigos e os crimes contra a sociedade e patrimônio público em geral. Alguns jornais mantêm o caderno policial, embora outros (os de grande circulação no país e no Estado do Paraná, essencialmente os pesquisados aqui) tenham optado por incluir assuntos criminais em cadernos usuais e de uma amplitude de pautas, como acontecimentos do cotidiano de uma região, de uma sociedade.

Essa é uma alteração gradual que pode ser observada na mídia, especialmente a escrita. Ressalta-se que a partir da década de 80, as reinvindicações pelo direito de comunicar-se e pela pluralidade de conteúdos fez-se mais presente no âmbito da sociedade brasileira, compondo, dessa maneira, um cenário de mobilizações da sociedade com o objetivo e apropriar-se das tecnologias e dos meios de comunicação em busca de uma democratização da comunicação (luta que sobrevive até hoje) pela dimensão dos Direitos Humanos e pela diversidade da cultura.

\section{Enquadramento}

Ao analisar o enquadramento noticioso (news frame) dos conteúdos dessas matérias é possível percebê-lo como um recurso simbólico para garantir a importância e a inteligibilidade da notícia, como um esquema de assuntos relacionados aos aspectos da realidade daquele conteúdo. Os estudos dos frames derivam inicialmente da sociologia de Goffman, com a finalidade de compreender como os sujeitos classificavam e organizavam suas "experiências de vida", sua cognição do mundo, isto é, como criavam os "esquemas de interpretação" ou "quadros de sentido" (GOFFMAN, 1974).

A identificação do enquadramento partiu do entendimento de Entman (1993), o qual observa a possibilidade de os mesmos definirem problemas, soluções, diagnósticos, causas, entre outros. Portanto, para o autor, essas funções de enquadramento podem ser identificadas a partir de uma frase ou mais. Desse modo, foram analisadas as frases que poderiam indicar o enquadramento do texto.

Na presente investigação, o enquadramento pode ser compreendido como o campo de análise da conotação da mensagem. Ou seja, a partir da observação dos textos, traduz-se a conotação da mensagem principal em formato de palavra-chave, como as mencionadas no Gráfico 1.

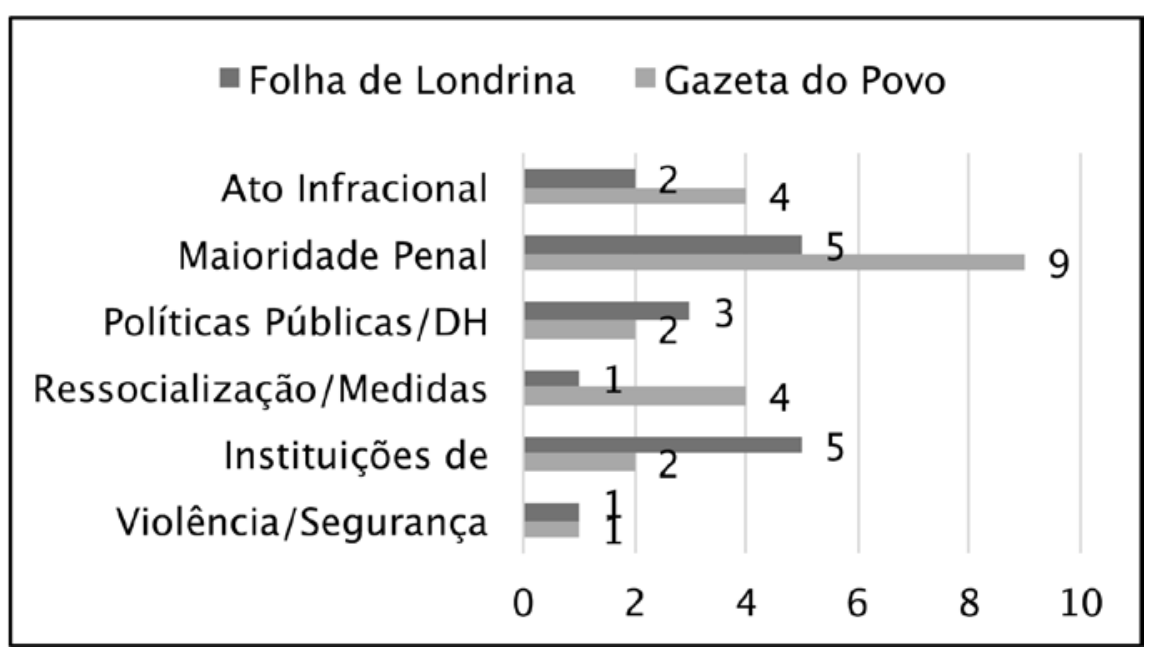

\section{Gráfico 1 - Enquadramento noticioso dos dois jornais Fonte: Dados da Pesquisa (2015).}

Das matérias pesquisadas que enquadram o ato delituoso em si, sem trabalhar um aprofundamento do caso, motivos, condições social, econômica e histórica do sujeito praticante, todas indicam uma produção noticiosa cujas fontes são exclusivamente da área policial e, por meio do estilo de texto, o boletim de ocorrência foi a fonte para a notícia. Boletins de ocorrência são os registros iniciais para a abertura do processo, sem aprofundamento no caso, embora nas notícias sobre os delitos com adolescentes sejam reproduzidos em forma de sentença. É o chamado “jornalismo de porta de delegacia”, no qual o Delegado é sempre a grande fonte do jornalista. 


\section{Como o adolescente é representado}

A pesquisa observou ainda o uso de vocábulos qualificativos e de tratamento em relação a esses adolescentes na cobertura dos atos infracioais, isto é, como esses sujeitos são apresentados nas mensagens.

Quanto aos vocábulos de tratamento mais empregados, tais como “jovem(ns)/adolescente(s)", aparecem 125 vezes sendo utilizados em todos os textos analisados. Os termos "menor infrator/ adolescente infrator/jovem infrator/infrator(es)/jovens detidos" são citados 50 vezes. e "adolescente/ jovem/menor em conflito com a lei/adolescentes autores de ato infracional", 27 vezes.

Termos como "assassino(s) e/ou adolescentes assassinos e/ ou pichadores" apareceram cinco vezes nos textos analisados; E "juventude perigosa", "bandidos violentos" e "jovens criminosos" aparecem, cada um dos termos, uma vez. Embora em menor frequência, esses vocábulos são pejorativos?, ultrajantes e possibilitam a produção de uma representação social negativa desses adolescentes. Como apresentado na Tabela 1, esses adjetivos correspondem a textos do jornal Gazeta do Povo.

O termo "menor" é citado algumas vezes, no entanto não é indicado seu emprego em razão do seu sentido pejorativo. Essa definição remete ao Código de Menores, que foi revogado pelo ECA em 1990. Observa-se que esses termos ainda são utilizados na mídia, ainda que a sugestão dos defensores de Direitos Humanos de crianças e adolescentes em conflito com a lei ressalte o uso de palavras pelos jornalistas que proporcione uma cobertura mais imparcial e distanciada, além de se atentarem ao usarem termos que contenham juízo de valor.

\begin{tabular}{|c|c|c|}
\hline Jornais/Vocábulos & $\mathbf{N}^{\circ}$ & $\%$ \\
\hline \multicolumn{3}{|l|}{ Gazeta do Povo } \\
\hline Jovem(ns)/adolescente(s) & 65 & $40,0 \%$ \\
\hline Menor infrator/adolescente infrator/jovem infrator/infrator(es)/Jovens detidos & 38 & $23,0 \%$ \\
\hline Adolescente/jovem/menor em conflito com a lei/adolescentes autores de ato infracional & 15 & $9,0 \%$ \\
\hline Menor(es)/menor(es) de idade & 15 & $9,0 \%$ \\
\hline Adolescentes internos/jovens internos/internados/interno(s) & 8 & $5,0 \%$ \\
\hline Meninos/meninas/garoto(s)/criança & 5 & $3,0 \%$ \\
\hline Assassino(s)/adolescentes assassinos/pichadores & 5 & $3,0 \%$ \\
\hline Jovens que cometem infrações graves/Adolescentes sujeitos a medidas restritivas de liberdade & 2 & $1,2 \%$ \\
\hline Adolescentes que cumprem medidas socioeducativas/Jovens em ressocialização & 2 & $1,2 \%$ \\
\hline Jovens que cometeram algum delito & 1 & $0,6 \%$ \\
\hline Juventude perigosa & 1 & $0,6 \%$ \\
\hline Bandidos violentos & 1 & $0,6 \%$ \\
\hline Jovens criminosos & 1 & $0,6 \%$ \\
\hline TOTAL & 161 & \\
\hline \multicolumn{3}{|l|}{ Folha de Londrina } \\
\hline Jovem(ns)/adolescente(s) & 60 & $54 \%$ \\
\hline Menor infrator/adolescente infrator/jovem infrator/infrator(es)/Jovens detidos & 12 & $11 \%$ \\
\hline Adolescente/jovem/menor em conflito com a lei/adolescentes autores de ato infracional & 12 & $17 \%$ \\
\hline Meninos/meninas/garoto(s)/criança & 11 & $10 \%$ \\
\hline Menor(es)/menor(es) de idade & 6 & $5 \%$ \\
\hline Adolescentes internos/jovens internos /internados/interno(s) & 5 & $4 \%$ \\
\hline Jovens que cometem infrações graves/Adolescentes sujeitos a medidas restritivas de liberdade & 3 & $3 \%$ \\
\hline Menino e menina & 1 & $1 \%$ \\
\hline Jovens em ressocialização & 1 & $1 \%$ \\
\hline TOTAL & 111 & \\
\hline
\end{tabular}

Tabela 1 - Vocábulos qualificativos aos adolescentes (maio/2013 a outubro/2014) Fonte: Dados da Pesquisa (2015).

7 Do latim pejorare, "tornar pior", de pejus, "pior". Pejorativo constitui uma palavra e/ou ideia cujo significado tende a depreciar e/ou insultar a ideia ou determinado sujeito. 
As narrativas dos meios de comunicação de massa atuam na construção da representação social e identitária, bem como influenciam os comportamentos sociais. Nesse sentindo, o emprego de palavras pejorativas e inadequadas pode reforçar o estigma e o estereótipo e, consequentemente, o preconceito. Com isso, o resultado pode ser de uma cultura da criminalização e estigmatização da criança e do adolescente que se envolve em atos infracionais.

Os dois jornais analisados (Gazeta do Povo e Folha de Londrina) são destinados aos estratos econômicos médios e altos da população, em grande parte distanciados cultural e espacialmente da realidade constituinte do modo e das condições de vida dos adolescentes em conflito com a lei, o que se reflete no processo de produção dos discursos midiáticos.

O foco principal dos dois jornais no período de maio de 2013 a outubro de 2014 foi a maioridade penal. A abordagem sobre o tema nos jornais converge com as pautas na televisão, no rádio, nas revistas e com os debates na internet motivados, principalmente, pelos últimos acontecimentos envolvendo delitos e adolescentes, os quais foram disseminados pelos meios de comunicação, muitas vezes pela internet, em formato de vídeos que, uma vez na web, tornam-se virais em pouco tempo.

É possível que a representação social e o estereótipo apareçam com mais frequência nos textos jornalísticos, uma vez que os profissionais da mídia, quando saem das suas redações para o local do acontecimento, geralmente já possuem modelos pré-estruturados em mente e passam a reconhecê-los e a reforçá-los em seus textos, isto é, os clichês ajudam a construir a notícia (MARCONDES FILHO, 2002).

A discussão sobre a maioridade penal sempre esteve presente na sociedade, mas é intensificada diante de um acontecimento divulgado por muitos meios massivos ou, como é o caso da pesquisa, cujo período coincidiu com o ano eleitoral no Brasil, no qual as promessas de campanha enfocaram, principalmente, a redução da maioridade penal em todas as hierarquias políticas (deputados estaduais, federais e senadores).

As associações de grande parte dos textos dos jornais com o tema da maioridade penal (44\%) promovem uma representação de que os casos de delitos cometidos por adolescentes são numerosos, alarmantes e são um risco contra a vida da população, sendo a redução da idade penal a solução. No entanto, dados do Mapa da Violência (2014) mostram que os jovens são as principais vítimas de morte por homicídio no país: em 2012, a taxa foi de 57,6 mortes por 100 mil jovens, um aumento de 2,7\% em relação ao ano de 2002, quando era de 56,1 por 100 mil jovens (de 15 a 29 anos). No Paraná, esse aumento, no mesmo período, foi de 51,1\%.

Percebe-se, nos jornais, a espetacularização da violência a partir da representação do menor de idade - seja pela preocupação em informar ou vender notícias (sob uma visão mercadológica). Dessa forma, os jornais tornam-se “indústrias do medo", proliferando a sensação de insegurança na sociedade.

Uma marca degenerativa, um ato de violência epistemológica, cuja identidade se torna desmembrada e deslocada da "dialética mente/corpo e resolvida na epistemologia da aparência e realidade” (BHABHA, 1998, p. 73).

Além disso, tendem a sofrer o que Bauman (2005, p. 46) chama de "ausência de identidade", ou seja, os grupos subalternos e minorizados não teriam o direito de reivindicar sua própria identidade, ou de tentar representá-la, uma vez que são sujeitos marginalizados, cabendo à sociedade construir sua representação identitária ou negá-la.

A partir do referencial teórico sobre a mídia, pode-se aferir que os meios de comunicação exerçam de alguma forma seu papel social, mas também são instrumentos políticos, constituintes por uma esfera de dominação, e não deixam de ser ideologicamente preocupados com as estratégias mercadológico-editoriais. O jornal tem liberdade em defender sua ideologia, informá-la aos leitores/consumidores e promover o debate social.

Krippendorf (1990) aponta três índices encontrados nas pesquisas de comunicação de massa:

(a) a frequência com que aparece um símbolo, ideia ou tema tende a ser interpretada como medida de importância, atenção ou ênfase. Nessa investigação, todas as categorias criadas foram consideradas de acordo com a frequência de exposição ou emprego. Vale ressaltar, essencialmente, 
as categorias que pomovem a representação de forma mais direta e, por consequência, possibilitam a construção identitária dos sujeitos envolvidos - os termos de cunho pejorativo, ou seja, aqueles que podem ofender, estigmatizar ou ultrajar o adolescente em conflito com a lei e os vocábulos qualificativos de tratamento.

(b) a quantidade de atributos favoráveis ou desfavoráveis desses elementos serve como medida de orientação e tendência. Observou-se que a quantidade determos evocábulos pejorativos, ou seja, com características desfavoráveis, possui a tendência de representar os adolescentes como "criminosos". Por outro lado, os jornais empregam alguns vocábulos qualificativos favoráveis, tais como "jovem(s)", "adolescente(s)", "adolescente/jovem em conflito com a lei”.

(c) a quantidade de associações e classificações manifestadas sobre esses elementos equivale à medida de intensidade ou força de uma crença, ideologia ou convicção. Com esse índice é possível notar que as associações dos textos sobre atos infracionais com a maioridade penal direcionam para a ideologia do jornal, deixando evidente sua posição no debate social, bem como a associação dos textos com outros temas além do enquadramento.

A Gazeta do Povo foi o periódico que se destacou pela posição qualitativa e quantitativamente mais crítica e pela cobertura aprofundada sobre a maioridade penal, ouvindo fontes sobre as mais variadas facetas do debate e informando, claramente, sua posição favorável à redução da inimputabilidade penal.

Por essas constatações, conclui-se que a Gazeta do Povo tem um tom mais incriminador em relação ao adolescente em conflito com a lei do que a Folha de Londrina.

Este último é o jornal com maior número de matérias com enquadramento sobre as instituições de socioeducação, publicadas no período proposto para análise e, sobretudo, com mais reportagens (10) a respeito dos adolescentes em conflito com a lei. Além disso, denuncia quantitativamente mais as mazelas que permeiam o sistema de ressocialização, tais como: os maustratos cometidos pelos educadores dos Centros de Socioeducação (CENSE); as irregularidades de infraestrutura desses locais e em relação às vagas para atender os adolescentes em medida de socioeducação de privação de liberdade; o crescimento do número de mortes de jovens no Paraná, entre outros. Essa associação é importante para a representação social, senão do adolescente em contravenção com a lei, do seu contexto, o que possibilita aos consumidores desses conteúdos refletir e inter-relacionar os debates sociais.

Diante dessas observações, conclui-se que a Folha de Londrina é o periódico que mais possui informações acerca do contexto da ressocialização com um viés no sentido de fazer parte das políticas públicas do país.

Do ponto de vista foucaultiano, as práticas discursivas são responsáveis por estabelecer a relação entre palavras e coisas, construindo, dessa maneira, as identidades (FOUCAULT, 2007). O autor ressalta que, nos sistemas de exclusão e de diminuição da densidade discursiva, delineia-se, por meio desta investigação, algumas relações de poder estabelecidas nos discursos dos jornais analisados. Ao trazer recortes do discurso jornalístico da Gazeta do Povo e da Folha de Londrina percebe-se que os adolescentes que cometeram delitos, seus familiares e o contexto dos sujeitos envolvidos são excluídos ou suas falas não são tratadas com credibilidade pelo jornalista.

Assim, é possível confirmar outros dois pressupostos da pesquisa: os jornais se caracterizam pela inserção de expressões verbais capazes de estigmatizar os adolescentes suspeitos de cometerem ato infracional; e a construção identitária desses adolescentes, produzida a partir do conteúdo da mídia impressa paranaense, está inserida numa herança dominante e normativa, resultando em um enquadramento bastante acentuado em percepções estereotipadas e estigmatizantes em relação a essa minoria.

\section{Considerações Finais}

Durante a investigação, a comunicação foi tratada como um processo intrínseco à sociedade, enquanto ação para a construção identitária e sua transformação social, essencialmente dos grupos minoritários. É também parte constituinte das minorias, pois estas se configuram como espaços de mediação e negociação social e política contra-hegemônica; um conjunto de vozes, que, por vezes, são silenciadas pela opressão. 
Na busca permanente da luta pelos Direitos Humanos dos sujeitos minorizados, analisouse como a mídia impressa pode construir a representação social e a identidade dos adolescentes em conflito com a lei. Para a apreciação, foram analisados 39 textos publicados em dois grandes jornais paranaenses - Folha de Londrina e Gazeta do Povo - entre o período de maio de 2013 a outubro de 2014.

Com a Análise de Conteúdo sustentada por Bardin (1977), Krippendorf (1990) e Fonseca Júnior (2012) foi possível o desenvolvimento de categorias que facilitaram a codificação e a decodificação dos elementos noticiosos pré-determinados e, sobretudo, alcançar os objetivos propostos, bem como sustentar as hipóteses construídas durante o processo da pesquisa.

Vale ressaltar que os resultados foram analisados de modo a construir uma compreensão sobre o tratamento narrativo da mídia escrita sobre esse grupo minoritário e como esse tratamento pode construir a identidade dos mesmos. Outrossim, esta investigação não almejou estudar como ou por que se dá o processo de produção desses conteúdos para que sejam abordados de tal maneira. No entanto, essa é uma sugestão para trabalhos futuros, uma vez que amplia o nível de entendimento e atende todo o circuito de produção cultural e comunicacional.

A partir das inferências produzidas por meio das análises das associações com temas e dos atributos favoráveis e desfavoráveis encontrados nos textos dos dois jornais, foi possível observar que as marcações sociais e simbólicas, associadas às representações sociais dos adolescentes em contravenção com a lei, nos conteúdos midiáticos são instauradas pelos jornais por meio da frequência de emprego de termos pejorativos e pelos vocábulos qualificativos que ainda são utilizados, bem como a associação dos acontecimentos à maioridade penal e um número muito baixo de debate em relação ao funcionamento das políticas públicas ou ao ECA, que não costuma fazer parte dos discursos.

Não se pode descartar o esforço dos profissionais dos dois jornais com o cuidado ao abordar o grupo minorizado, ao seguir as orientações dos defensores dos Direitos Humanos infantojuvenis. É notável a mudança no discurso jornalístico dos últimos anos. No entanto, nesta investigação, em um período em que o número de debates sobre a questão do adolescente que comete ato infracional no país foi numeroso, foram verificadas várias observações de exposição desfavorável aos adolescentes.

Sua representação dá significado a uma identidade construída midiaticamente, pelos jornais Gazeta do Povo e Folha de Londrina, pela diferença e exclusão dos próprios meios de comunicação: sua marcação simbólica se concentra no ato infracional cometido, nas consequências dos seus atos, na "punição" de permanecer privado da liberdade por transgredir os limites da sociedade e, principalmente, no que o adolescente "se torna" ao cometer algum delito - nota-se que os jornais não discursam sobre o que e quem o adolescente "era", apenas no que ele "é" depois da infração: um sujeito transgressor cuja Lei n 8.069/1990 protege ao invés de "castigar".

A pesquisa sinaliza para uma mídia impressa que não discute os motivos que levam à transgressão. Os jornalistas tendem a não conhecer as realidades desses meninos transgressores. Não se lê sobre sua história de vida, não têm familiares dos adolescentes como fontes noticiosas. Eles só existem sob representação de números e palavras que não são deles.

A dinâmica estrutural, social e política da contemporânea sociedade da informação implica novos posicionamentos dos sujeitos, novas configurações dos meios de comunicação e, principalmente, a ruptura de paradigmas e estereótipos. A comunicação serve para pensar, trazendo a reflexão crítica e permitindo transformar o pensamento - antes linear, rígido, marcado pela fixidez - em conhecimento e aprendizagem a partir da interação dialógica entre indivíduos e meios de comunicação massivos.

O diálogo entre a sociedade e os meios de comunicação deve servir como palco para o desdobramento dos dados apresentados, uma vez que constituem agências responsáveis pela socialização de crianças e adolescentes. Espera-se que os resultados da pesquisa contribuam para a mobilização em torno de uma comunicação para a reflexão crítica, com mídias mais promotoras de direitos desse público. Além disso, a prática de políticas de comunicação que atendam a promoção e proteção dos Direitos Humanos das crianças e adolescentes deve ser prioridade na atual conjuntura social. 


\section{Referências}

BARDIN, L. Análise de conteúdo. Lisboa: Edições 70, 1977.

BAUMAN, Zygmunt. Identidade: Entrevista a Benedetto Vecchi. Tradução de Carlos Alberto Medeiros. Rio de Janeiro: Editora Jorge Zahar, 2005.

BHABHA, Homi K. O local da cultura. Belo Horizonte: Editora da UFMG, 1998.

BRASIL. Estatuto da Criança e do Adolescente. Lei no 8.069 de 13 de julho de 1990. Dispõe sobre o Estatuto da Criança e do Adolescente e dá outras providências. Brasília, DF, 1990.

PRESIDÊNCIA DA REPÚBLICA. SECRETARIA DE DIREITOS HUMANOS (SDH). Levantamento anual dos/as adolescentes em conflito com a lei - 2012. Brasília: Secretaria de Direitos Humanos da Presidência da República, 2013.

CANCLINI, Nestor G. Diferentes, desiguales y desconectados: mapas de la interculturalidad. Barcelona: Editora Gedisa, 2004.

CREAS. Cartilha de medidas socioeducativas. Centro de Referência Especializado de Assistência Social - CREAS. Fundação de Assistência Social - FAS, Curitiba, s/d, 12p.

DURKHEIM, Émile. Representações individuais e representações coletivas. Rio de Janeiro: Forense Universitária, 1970.

ENTMAN, Robert M. Framing: toward clarification of a fractured paradigm. In: Journal of Communication, n. 43, 1993.

FONSECA JÚNIOR, Wilson Corrêa. Análise de conteúdo. In: DUARTE, J.; BARROS, A. (orgs.). Métodos e técnicas de pesquisa em comunicação. 2. ed. São Paulo: Atlas, 2012.

FOUCAULT, Michel. Vigiar e punir: história da violência nas prisões. Petrópolis: Vozes, 2007.

GOFFMAN, Erving. Frame analysis: an essay on the organization of experience. Cambridge: Havard University Press, 1974.

Estigma: notas sobre a manipulação da identidade deteriorada. $4^{a}$ ed. Rio de Janeiro LTC Editora, 2012.

HALL, Stuart. Identidade cultural e diáspora. In: Revista do Patrimônio Histórico e Artístico Nacional. Rio de Janeiro, IPHAN, 1996, p. 68-75.

Quem precisa de Identidade? In: SILVA, Tomaz Tadeu da. (Org.). Identidade e diferença: a perspectiva dos estudos culturais. 14ª ed. Petrópolis/RJ: Vozes, 2014.

KELLNER, Douglas. A cultura da mídia. Tradução de Ivone Castilho Benedetti. Bauru: Edusc, 2001. KRIPPENDORF, Klaus. Metodología del análisis de contenido. Barcelona: Paidós Ibérica, 1990.

MARCONDES FILHO, Ciro. Comunicação e jornalismo: a saga dos cães perdidos. São Paulo Hacker, 2002.

MOSCOVICl, Serge. Representações sociais: investigações em psicologia social. Trad. Pedrinho A. Guareschi. Rio de Janeiro: Vozes, 2003.

OROZCO, Guilhermo G. Comunicação social e mudança tecnológica: um cenário de múltiplos desordenamentos. In: MORAES, Dênis de. (Org.). A Sociedade midiatizada. Rio de Janeiro: Mauad, 2006.

WOODWARD, Kathryn. Identidade e diferença: uma introdução teórica. In: SILVA, Tomaz Tadeu da. (Org.). Identidade e diferença: a perspectiva dos estudos culturais. 14ª ed. Petrópolis/RJ: Vozes, 2014. 